\title{
A Calculation Program for the Characteristic Frequency of Mechanical Fault Diagnosis
}

\author{
Chun Lv ${ }^{1}$ a , Peilin Zhang ${ }^{1}$, Chao $\mathrm{Xu}^{1}$, Yunqiang Zhang ${ }^{1}$,Yining $\mathrm{Li}^{1}$ \\ ${ }^{1}$ Seventh Department, Ordnance Engineering College, Shijiazhuang, 050003, China \\ aemail: Ivchun18@163.com
}

Keywords: fault diagnosis; characteristic frequency; program

\begin{abstract}
In order to solve the problem that the traditional fault diagnosis for the transmission system of self-propelled guns cannot access accurate fault locating due to the lack of effective methods [1], a program for calculating the characteristic frequency of the transmission system was developed. In this paper, we calculate the characteristic frequency of shaft, gears, bearings and other typical rotating parts and establish relatively complete database by the transmission regular on the basis of the engine crankshaft speed, so that we can make effective identification and feature extraction in equipment state detection and diagnosis.
\end{abstract}

\section{Introduction}

Self-propelled gun is an integrated firing weapon which work in severe environment, such as high speed and heavy load, so it is easy to be damaged and the failure rate is high [2]. Furthermore, its structure is complex and expensive, in witch the transmission system is a key member whose failure will directly affect the combat capability [3]. It is of great importance to calculate the characteristic frequency of the transmission system. The transmission system which is generally used in the late- model self-propelled gun have following characteristics: Its structure is more complex; the system integration degree is higher; it is more difficult to make condition monitoring and fault diagnosis of the transmission system. It is a pressing need that we develop a quick method to access accurate fault locating of the system.

\section{Design of the program}

According to the research objective, the program must have good generality. We find out the commonness in various artillery when calculating the gear mesh frequency and shaft frequency, as shown in figure 1. 


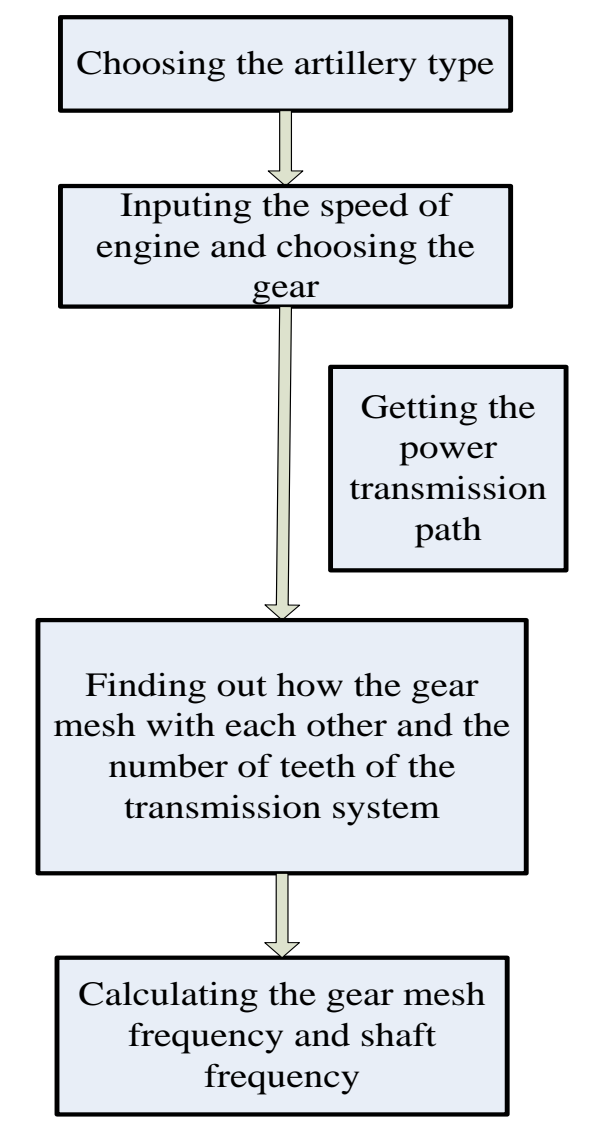

Fig.1. Program design process

Each gear transfer path, the number of gear teeth, gear meshing relationship were stored in different data sheet, wherein the meshing relationship are represented by analytical code, such as a, b, c, etc. As shown in the following table.

Gear analytic code notes

\begin{tabular}{|c|c|c|c|c|c|c|c|c|c|}
\hline Gear type & $\begin{array}{c}\text { Driving } \\
\text { gear }\end{array}$ & $\begin{array}{c}\text { Driven } \\
\text { gear }\end{array}$ & $\begin{array}{c}\text { Mid } \\
\text { gear }\end{array}$ & $\begin{array}{c}\text { In-line } \\
\text { gears }\end{array}$ & $\begin{array}{c}\text { Planetary } \\
\text { gear ring }\end{array}$ & $\begin{array}{c}\text { Planet } \\
\text { carrier }\end{array}$ & $\begin{array}{c}\text { Planetary } \\
\text { frame } \\
\text { outputting } \\
\text { gear }\end{array}$ & $\begin{array}{c}\text { Planet } \\
\text { wheel }\end{array}$ & $\begin{array}{c}\text { Sun } \\
\text { wheel }\end{array}$ \\
\hline $\begin{array}{c}\text { Analytical } \\
\text { code }\end{array}$ & $\mathrm{a}$ & $\mathrm{b}$ & $\mathrm{c}$ & $\mathrm{d}$ & $\mathrm{q}$ & $\mathrm{j}$ & $\mathrm{e}$ & $\mathrm{x}$ & $\mathrm{t}$ \\
\hline
\end{tabular}

The power output from the engine, the number of driving gear teeth multiplied by the engine speed is driving gear meshing frequency [4].According to the analytical code of the gear which are meshed with the driving gear, we select corresponding formula to calculate the meshing frequency and the shaft frequency, and so on, along the power transmission path, meshing frequency and shaft frequency of all the gear which mesh with others are calculated [5]. In order to make the program is of generality, we need to establish related database. When add new model artillery, we only need to add each gear transfer path, the number of gear teeth, and analytical code of gear and shaft into the corresponding table in the database, then we can calculate the meshing frequency and shaft frequency by running the program [6].

\section{The application of database}

Considering the characteristics of each database program and the actual needs of the project, Access is selected as the database program. Each gear transfer path, the number of gear teeth, gear meshing relationship were stored in different data tables, as shown in figure 2. 


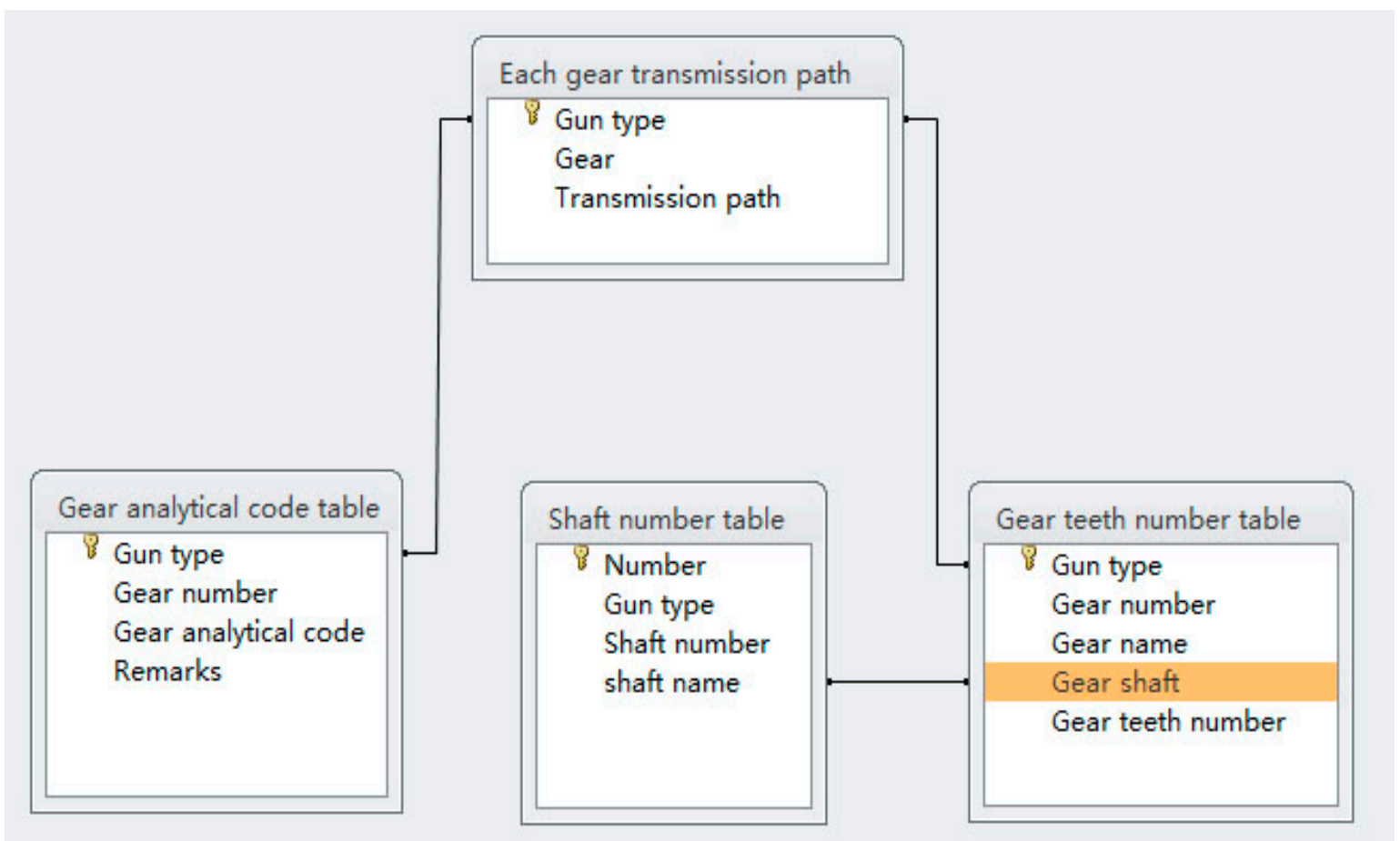

Fig.2. The diagram of the database structure

1. The table of each gear transmission path contains the following fields: Gun type, Gear, Transmission path, wherein transmission path is expressed as $1-2-3-6-4-8-9 \cdots \cdots$, in which the number represents a gear, as shown in figure 3.

$\begin{aligned} & \text { Each gear transmission path } \\
& \text { Gun type }\end{aligned}$ Gear
\begin{tabular}{|l|l|} 
A type of gun Seventh gear & $1-2-3-4-5-6-7-10-11-12-8-24-25$ \\
\hline A type of gun Third gear & $1-2-3-4-5-6-7-10-11-12-8-9-24-25$ \\
\hline A type of gun Sixth gear & $1-2-3-4-5-6-7-10-13-14-8-24-25$ \\
\hline A type of gun Second gear & $1-2-3-4-5-6-7-10-13-14-8-9-24-25$ \\
\hline A type of gun Fifth gear & $1-2-3-4-5-6-7-10-15-16-8-24-25$ \\
\hline A type of gun First gear & $1-2-3-4-5-6-7-10-15-16-8-9-24-25$ \\
\hline A type of gun Climbing gear & $1-2-3-4-5-6-7-10-17-18-8-9-24-25$ \\
\hline A type of gun Reverse gear & $1-2-3-4-5-6-7-10-19-20-21-8-9-24-25$ \\
\hline A type of gun Eighth gear & $1-2-3-4-5-6-7-8-24-25$ \\
\hline A type of gun Fourth gear & $1-2-3-4-5-6-7-8-9-24-25$ \\
\hline
\end{tabular}

Fig.3. Each gear transmission path table

2. The table of gear teeth number table contains the following fields: gun type, gear number, gear name, gear shaft, gear teeth number.

3. The table of gear analytical code table contains the following fields: gun type, gear number, gear analytical code and remarks. The meshing relationship is expressed by the analytical code: the driving gear is a; the driven gear is b; the intermediate gear is c; the coaxial gear is $\mathrm{d}$; the sun wheel is $t$, the planet wheel is $x$, the planetary gear ring is $q$, the planet carrier is $j$.

4. The table of shaft number table contains the following fields: number, gun type, each shaft number, shaft name.

\section{Verification of the program}

We take first gear as an example and calculate its transmission ratio. Run the program to calculate each shaft frequency, as shown in figure 4 .The following results are obtained:

$n_{\mathrm{G}}=0.0166, n_{\mathrm{H}}=0.0067, n_{\mathrm{L}}=0.0019$

So the transmission ratio of first gear is :

$i_{1}=\left(n_{G} / n_{H}\right) *\left(n_{H} / n_{L}\right)=(0.0166 / 0.0067) *(0.0067 / 0.0019)$

$=2.47 * 3.43=8.4721$ 
The result is consistent to actual transmission ratio.

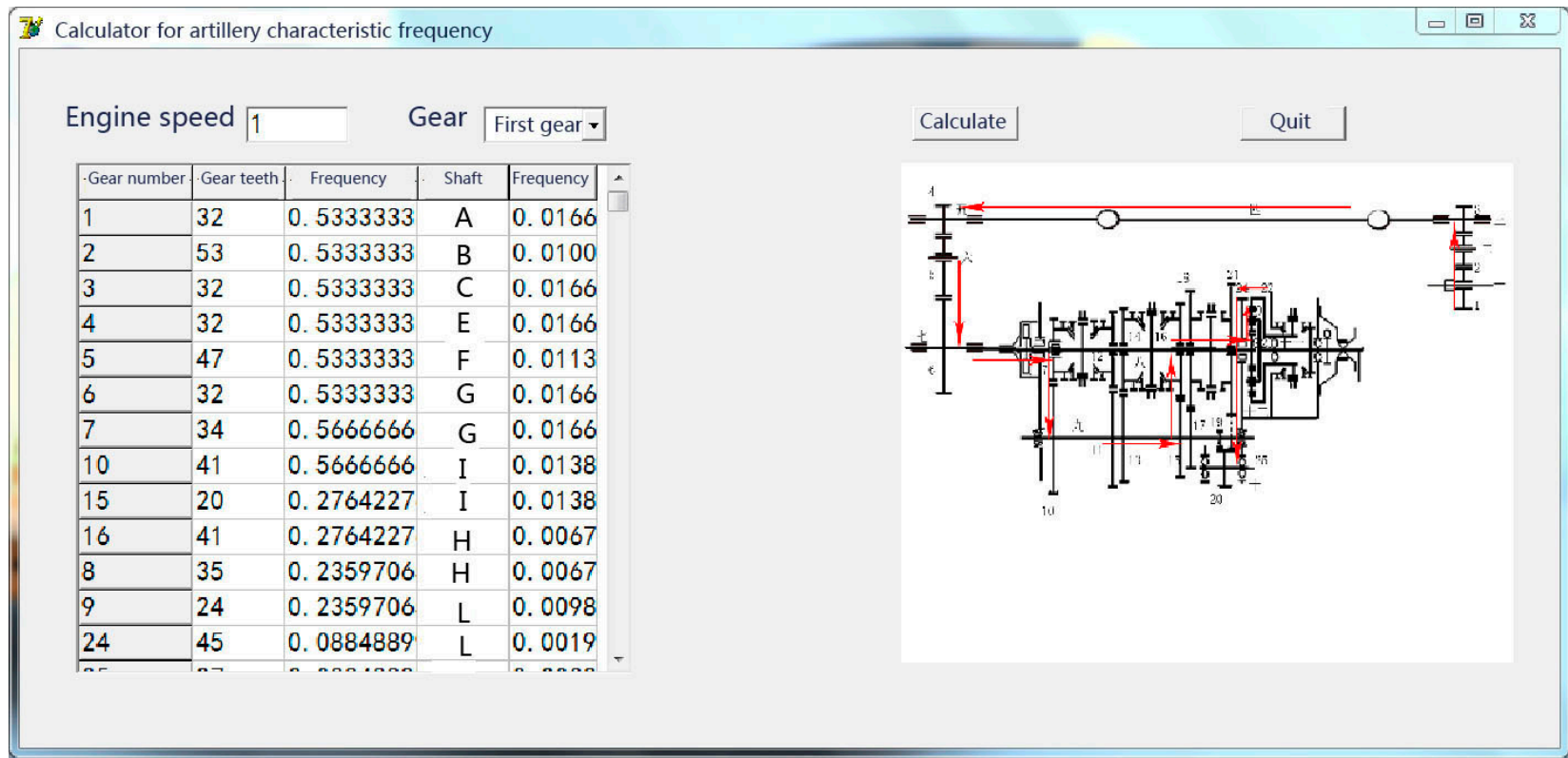

Fig.4. The result of running program

\section{Conclusion}

In this paper, we develop a program for calculating the characteristic frequency of the artillery transmission system. The result of the final experiment proves the accuracy of the program. The program not only offer a good solution to the disadvantages of traditional way, which have long cycle, high error rate and poor generality, but also lay a good foundation for rapid positioning of fault diagnosis.

\section{Reference}

[1] Yang Jiankui, Gao Guohua, Sun Zili, et al. Rolling Bearing Fault Diagnosis Based on Demodulated Resonance Analysis [J]. Coal Mine Machinery, 2004:

[2] Zhang Bibo. Equipment Condition Monitoring and Fault Diagnosis[M]. Chemical Industry Press, 2001.

[3] Li hui, Liu xin. Delphi Application Development Paradigm Collection (Third Edition)[M]. People's Posts and Telecommunications Press, 2012

[4] Han Jie, Zhang Ruilin, et al. Fault Mechanism and Diagnosis Technology of Rotating Machinery[M]. Machinery Industry Press, 1996.

[5] Ding kang, li Weihua, Zhu Xiaoyong. Practical Technology of Gear and Gear Box Fault Diagnosis[M]. Machinery Industry Press, 2006.

[6] Ma Xiang. Research on Small Gearbox Detection and Fault Diagnosis[D]. Xi'an Science and Engineering University, 2003. 